\title{
Growth relations between individual fruits, and between fruits and roots in cucumber ${ }^{1}$
}

\author{
H. C. M. de Stigter \\ Centre for Plant Physiological Research, Wageningen, the Netherlands
}

Received 21 January 1969

\section{Summary}

In a drastically reduced 'shoot-fruit-root' system pronounced relations were observed between individual fruits, and between fruit and root growth. These effects, directly and obviously related to the individual organs, are probably of the same nature as the more indirect, 'statistical' or 'mass' effects described by others in 'conventional' plants, under more normal growing conditions. The system described offers more convenient possibilities for experimental manipulation.

\section{Introduction}

Some plants, like melon, egg-plant and, under circumstances, cucumber, show the phenomenon of periodic or cyclic fruit setting, by which is meant that periods or cycles of fruit setting and fruit growth alternate with periods in which new flowers largely or completely fail to set. This phenomenon is brought about by the plant's total fruit producing capacity being limited by the size of its vegetative apparatus, as determined by environmental conditions, e.g. the nitrogen level of the soil (Cunningham, 1939; Fujii and Itagi, 1955; Matsuzaki and Hayase, 1963). Conversely, a heavy fruit load exerts a checking effect on vegetative growth. This is most readily observed in the above-ground vegetative parts (Murneek, 1926), but appears to be also true for the much less accessible root system (van der Meijs, 1966; van der Post, 1968; van der Meijs and van der Post, 1968).

Generally, these observations are pictured as effects of competition among the various organs for food materials, the fruits as a whole being the winning party. Given a certain balance between vegetative and reproductive growth, however, there is also competition between individual fruits, the larger ones tending towards monopolizing the available building materials, and the smaller ones (and flowers and buds) running the risk of premature shedding or abnormal development. This readily explains the experience that cucumber plants will produce a much greater number of fruits if these are picked in an early stage (Carlsson, 1962; Hallig and Amsen, 1967). Picking the fruits at $220 \mathrm{~g}$ and $350 \mathrm{~g}$ target-weight, the latter authors obtained $29 \%$ more cucumbers of the smaller size, though at a loss in total weight of $7 \%$.

In all of the above mentioned papers, the observations on growth interactions be-

1 Publication No 79, Centre for Plant Physiological Research (P.O. Box 52), Wageningen, the Netherlands. 
tween fruits and vegetative organs were made in plants grown under as nearly normal horticultural conditions as compatible with the special objectives of the various studies concerned. In this paper, on the ofher hand, we will present similar results obtained under more divergent conditions, but of a more immediate obviousness.

Attempting to make an experimental approach to the rather capricious phenomenon of 'graft-chlorosis' in cucumber grafted on Cucurbita ficifolia, and having only limited greenhouse space available in our institute, we were forced to reduce the normally very robust plant to a fruit-bearing system with as few leaves as practicable. For this purpose, we could make a grateful use of Hille Ris Lambers' finding (not published, personal communication; see further 'Material and methods'), that cucumber plants will produce pistillate flowers at a very young age, if topped above the second leaf as soon as this leaf separates from the growing tip.

At the same time we were developing a special method of water culture enabling us to make frequent and accurate observations on growth of individual roots.

Below, some of the results obtained will be reported.

\section{Material and methods}

For the experiments cucumber plants of an old cultivar, 'Lentse Gele', were used. Seeds were germinated in vermiculite, and the seedlings transferred to water culture. By pinching the growing tips above the second leaf, as soon as practicable, the plants were stimulated to produce pistillate flowers when still very young. In a preliminary experiment the leaf apparatus was kept restricted to the original two leaves, but these soon began to show severe discolorations, and in most cases only one pistillate flower arose. Therefore later on axillary shoots were allowed to develop, and these were pinched above the first leaf, this leaf again producing an axillary shoot, of the second order, and a pistillate flower. The second order shoots were treated as the first order ones, in their turn producing third order shoots and pistillate flowers, and so on (see Fig. 1).

Measurements of growth in length of the ovary parts of the female flower buds were started as soon as possible, and the days of anthesis noted. On the day of opening, the flowers were hand-pollinated, to obtain fruit set, as this particular cultivar did not show a very pronounced tendency towards parthenocarpy under the experimental conditions described.

For measuring growth of individual roots, the plants were grown with their root systems spread on black nylon cloth bathed in nutrient solution, in shallow slanting trays with removable light-tight lids; for a detailed description of this method, see de Stigter (1969). Per plant, some five of the best growing roots were selected for being measured.

\section{Results and discussion}

\section{Interactions between individual fruits}

Fig. 2 and 3 give an impression of the kind of reactions observed as to the growth of individual fruits. These reactions can be characterized as the taking dominance by one, usually the first, fruit over all the following ones. Fig. 2 pictures an extreme 


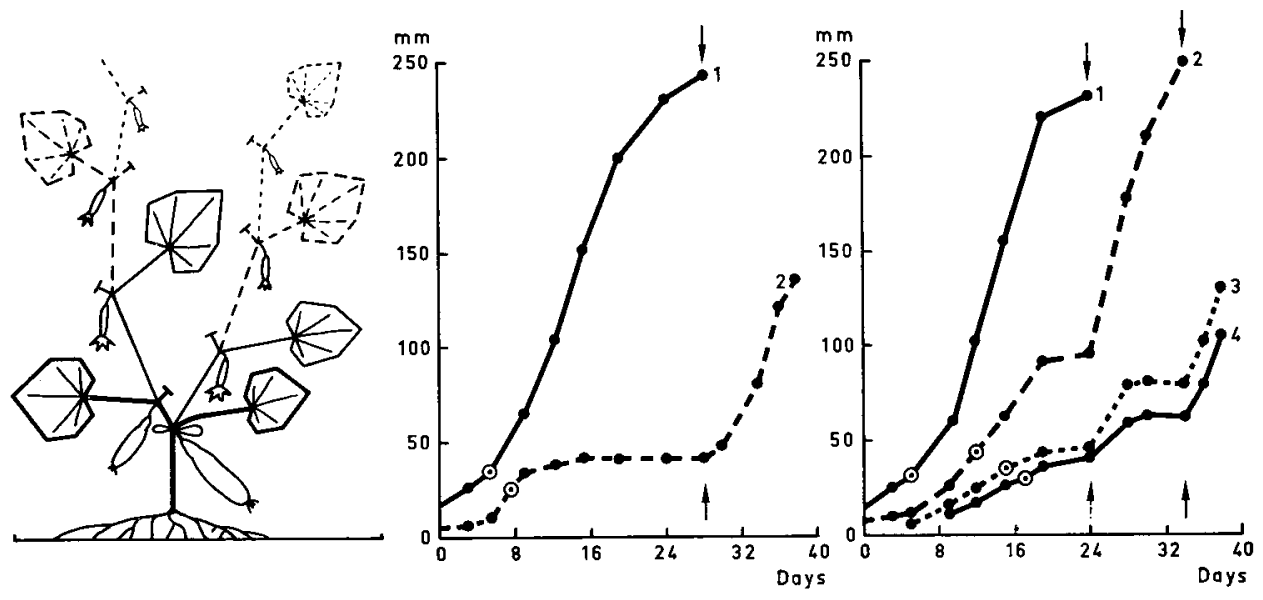

Fig. 1 Schematic representation of treatment for inducing young cucumber plants to form pistillate flowers at an early stage and to set fruit with a drastically reduced leaf apparatus.

main stem with first two leaves, topped above the second leaf.
first order laterals arising by topping of main stem, with one leaf allowed to grow out, and topped above this leat.

_..... second order laterals with one leaf and topped above this leaf.

third order laterals, etc.

At all nodes (often also at cotyledonary level) one or more pistillate flowers are formed.

Fig. 2 Growth curves (total lengths in $\mathrm{mm}$ against time in days) of individual cucumber fruits on one plant. Extreme case of dominance of first fruit over subsequent one. After harvest of leading fruit (= fruit 1 ), on day 28 (weight $360 \mathrm{~g}$ ), fruit 2 immediately starts growing. Flowers were pollinated on day of opening, indicated by $\odot$.

Fig. 3 Growth curves (total lengths in $\mathrm{mm}$ against time in days) of individual cucumber fruits on one plant. Dominance of fruit 1 over fruit 2 less pronounced, but still evident, especially by very rapid growth of fruit 2 after harvest of fruit 1 (weight $377 \mathrm{~g}$ ), on day 24. Fruits 3 and 4 , also resuming growth after day 24, soon become inhibited by fruit 2 , but once again start rapid growth after harvest of this fruit (weight $254 \mathrm{~g}$ ), on day 34.

case of such a dominance: pollinated flower 2 was completely inhibited, or nearly so, during several weeks, but started a rapid growth as soon as the leading fruit was harvested. The growth curve of fruit 3 is not shown in this picture because it was very similar to that of fruit 2 ; toward the end of the experiment, however, fruit 3 in its turn became distinctly dominated by fruit 2 .

Sometimes there were two, more or less equivalent leading fruits, but in most cases inhibition occurred from the second fruit on. Fig. 3 shows a case where fruit 2 clearly made initial growth but became inhibited one week after pollination, to resume very rapid growth after fruit 1 was harvested.

In order to reduce the observational material to a common numerical basis, one possibility would be to mathematically relate the growth curves of all the 2 nd, 3 rd, etc. fruits of the various plants to the sigmoidal growth curves of the leading fruits of these plants. This, however, would lead to a rather complicated result. Therefore, in a simplified approach, we adopted the average growth per day, from pollination to harvest, of the leading fruits as a quantity of reference. Then we calculated the average growth per day of the $2 \mathrm{nd}$, 3rd, and 4th fruits (1) from their pollination to 
Table 1 Average growth rates of fruits 2, 3 and 4, as percentages of average growth per day of fruit 1, before and after harvest of latter. Between brackets, in last two columns: values for fruits of plant represented by Fig. 3

\begin{tabular}{|c|c|c|c|c|c|c|}
\hline & \multirow[t]{2}{*}{$\begin{array}{l}\text { Average } \\
\text { weight } \\
\quad(g)\end{array}$} & \multirow[t]{2}{*}{$\begin{array}{l}\text { Average } \\
\text { length } \\
(\mathrm{mm})\end{array}$} & \multicolumn{2}{|c|}{$\begin{array}{l}\text { Average growth per } \\
\text { day of fruit } 1 \text { from } \\
\text { pollination to harvest }\end{array}$} & \multirow{2}{*}{$\begin{array}{l}\text { Average growth per } \\
\text { day following fruits, } \\
\text { from pollination to } \\
\text { harvest of fruit } 1 \text {, as } \\
\text { \% of growth rate } \\
\text { of fruit } 1\end{array}$} & \multirow{2}{*}{$\begin{array}{l}\text { Average growth per } \\
\text { day of following } \\
\text { fruits, after harvest } \\
\text { fruit } 1 \text {, as \% of } \\
\text { growth rate of fruit } 1\end{array}$} \\
\hline & & & $(\mathrm{mm})$ & $(\%)$ & & \\
\hline Fruit 1 & 334 & 237 & 10.5 & 100 & - & - \\
\hline Fruit 2 & 170 & 179 & - & - & $42.4(41.1)$ & $97.0(147.2)$ \\
\hline Fruit 3 & 14.9 & 83 & - & - & $15.4(11.6)$ & $58.7(57.0)$ \\
\hline Fruit 4 & 8.7 & 60 & - & - & $11.2(14.9)$ & $41.3(42.1)$ \\
\hline
\end{tabular}

the moment of harvest of the leading fruit, and (2) from this moment to the end of the experiments, expressing these numbers as percentages of the first mentioned reference values. Finally, the average growth rates of all the individual 2 nd, 3rd, and 4th fruits during the two periods mentioned could be calculated as percentages of the average growth rate of the leading fruits. Table 1 summarizes the results of these calculations, together with the final weights and lengths of the fruits.

As can be seen from the table, fruits 2 on the average grew less than half as fast as the dominating fruits, and the subsequent fruits still less, but after the dominating fruits were harvested, the growth rates of fruits 2 more than doubled, while those of fruits 3 and 4 almost quadrupled. In the last two columns of Table 1, between brackets, the values are given of the plant pictured in Fig. 3. These values being closely similar to the average ones, we can say that Fig. 3 presents a visual impression of the average growth relations between the dominating first fruits and the subsequent, inhibited fruits found in these experiments. Meanwhile, in Fig. 3 the phenomenon of dominance and inhibition is repeated: after fruit 1 was harvested, on day 24, fruits 2,3 and 4 started a rapid growth, but because of dominance, now by fruit 2 , fruits 3 and 4 soon became inhibited for the second time, once again resuming a rapid growth after fruit 2 was harvested, on day 34. Again applying the above calculations, this time taking the average growth rate of fruit 2 between the 24th and 34th days as a reference $(15.5 \mathrm{~mm} /$ day $)$, the growth rates of fruits 3 and 4 , between days 24 and 38 , before and after harvest of fruit 2 , were: $21.9 \%$ and $12.3 \%$, and $80.6 \%$ and $69.3 \%$, respectively.

Returning to Fig. 2, it is interesting to note that apparently a fertilized cucumber ovary can stay in a resting stage for a surprisingly long period (about two weeks) without losing the capacity of resuming normal growth.

\section{Effects of fruits on root growth}

The above observations on interactions between individual fruits were made at a time when our installation for root growth studies as mentioned under 'Material and methods' was not yet completed. The rather inaccurate and incomplete root measurements made at that time nevertheless suggested that developing fruits exert an inhibitory effect upon root growth. This impression became fully confirmed in later experiments using the completed installation. 


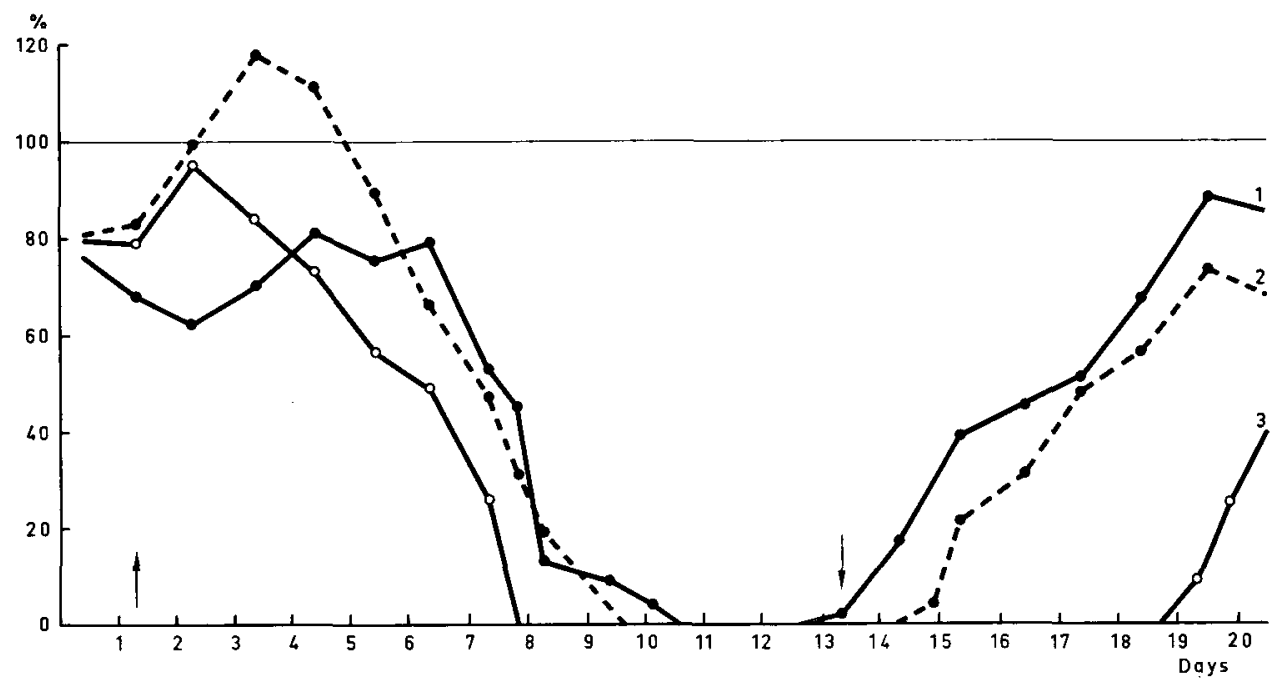

Fig. 4 Effect of growing fruit on root growth. Growth curves of 3 individual roots of one plant, expressed as percentages of average root growth in three plants without any fruits, plotted against time in days. Upward arrow: one pistillate flower open, and pollinated; downward arrow: fruit harvested, 12 days later, weighing $245 \mathrm{~g}$.

Fig. 4 pictures root growth of a cucumber plant, prior and subsequent to pollination of one pistillate flower, expressed as percentage of the average root growth of three plants without any fruits. In the beginning, measurements were also made of the fruit of this plant, but as this fruit soon became very crooked, the measurements were discontinued after a few days. Y' et, fruit growth was very rapid: the measurements on four consecutive days gave as results, starting with $37 \mathrm{~mm}$ at pollination, 47, 63, 85 and $108 \mathrm{~mm}$, the growth increments thus being 10,16, 22 and $23 \mathrm{~mm}$ on these first four days after pollination. Twelve days after pollination this fruit was harvested, weighing $245 \mathrm{~g}$.

From Fig. 4 it is evident that some 3-4 days after pollination root growth began to decrease; this decline continued until root growth stopped completely, while harvesting of the fruit resulted in a gradual recovery of root growth. Actually, some resumption of root growth already became apparent before fruit harvest, but a real and lasting recovery occurred only after the fruit was removed from the plant. It is still possible, however, that roots might have grown slightly if the fruit had been left on the plant. If this would be true, this could mean that after a certain stage of development has been reached, the checking effect of fruits on root growth will decrease. This point is to be studied in further experiments.

As can also be seen in Fig. 4, the individual roots stopped growing in a certain order, and resumed growth in the opposite order: the earliest to stop were the last to start again, and the last to stop were the first to start again. The longest period of complete root-growth cessation in this experiment was 11 days. As already commented on with respect to fruit growth, apparently roots, too, can stand prolonged periods of complete growth arrest without losing the capacity of resuming normal growth. A point of further interest concerns the degree to which such inhibited roots continue to carry on their functions of water and mineral absorption. 
For the time being, the most plausible hypothesis to explain the checking effect of developing fruits on root growth is to assume the coming into action of a strong power of monopolizing food materials, seated in (certain parts of) the young fruit, and brought about by hormonal factors. To explain the differences between individual roots just mentioned, on the other hand, there are several possibilities. One possibility is to assume that between roots a similar competition occurs, activated, here too, by differences in hormone level. Quite different, but nevertheless conceivable, is another possibility: that the transport channels from the supplying leaves to the root system are influenced by the fruits' monopolizing action (e.g. by obliteration of sieve tubes) but to a different degree, so that roots with more direct or less affected phloem connexions continue growing longer and recover earlier. Still, it is also possible that these two factors work simultaneously, and are somehow interrelated. Direct evidence for any particular possibility is not available, and would certainly be hard to come by. We must finally question how far our observations on drastically reduced 'shootfruit-root' systems are directly comparable to results with 'conventional' complete plants, as reported by Hallig and Amsen (1967) on numbers of cucumbers obtained if harvested at different sizes, or by van der Meijs (1966), van der Post (1968), and van der Post and van der Meijs (1968) on relations between root growth and crop development. Most probably, our respective results are indeed fundamentally alike, i.e. as to the causing agents involved. The difference is that the other authors' results to some degree may be typified as 'statistical' or 'mass' effects: effects of the whole of growing fruits on subsequent fruit set and fruit growth; the combined effect of developing fruits on root growth as a whole, while our observations, though indicating the same kind of relationships, are doing so in a more direct way: effects of individual fruits on other individual, nearby fruits, and effects of one or at most a few growing fruits on growth of individual roots. Therefore, in more physiologically directed studies, with no immediate aim of practical applicability, our system offers more convenient possibilities for experimental manipulation.

\section{References}

Carlsson, G., 1962. Studies of factors affecting the yield and quality of cucumbers. I. Fruit length and fruit-setting. Acta Agric. scand. 12: 355-362.

Cunningham, C. R., 1939. Fruit setting of watermelons. Proc. Am. Soc. hort. Sci. 37: 811-814.

Fujii, T. and Itagi, T., 1955. Studies on the cyclic setting of fruit in egg-plant. J. hort. Ass. Japan 23: $1-8$.

Hallig, V. Aa. and Amsen, M. G., 1967. Udbytte og kvalitet hos agurker i vaeksthus, når frugterne h $\phi$ stes i 3 størrelser (Yield and quality of cucumbers under glass when the fruits are harvested at 3 sizes). Tidsskr. PlAvl 71: 366-373.

Matsuzaki, A. and Hayase, H., 1963. (Studies on fruit growth of cucumber. I. Relation between fruit set and nitrogen supply). J. Jap. Soc. hort. Sci. 32: 121-129.

Meijs, M. Q. van der, 1966. Wortelontwikkeling bij komkommer, tomaat en paprika. JVersl. Proefstn Groente-en Fruitteelt Glas Naaldwijk 1966: 101-103.

Murneek, A. E., 1926. Effects of correlation between vegetative and reproductive functions in the tomato (Lycopersicon esculentum Mill.). Pl. Physiol. 1: 3-55.

Post, C. J. van der, 1968. Simultaneous observations on root and top growth. Acta Hort. 7: 138-143.

Post, C. J. van der and Meijs, M. Q. van der, 1968. Relatie tussen wortelgroei en gewasontwikkeling bij enige groentegewassen onder glas. With summary: Relationships between root growth and crop development of some vegetables under glass. Meded. Dir. Tuinb. 31: 447-452; summary p. 464.

Stigter, H. C. M. de, 1969. A versatile irrigation-type water culture for root-growth studies. $Z$. PflPhysiol. 60: 289-295. 